Шушпанова Ирина Сергеевна - кандидат социологических наук, доцент, ученый секретарь, ведущий научный сотрудник Института социально-политических исследований ФНИСЦ РАН. Адрес: 119333, Россия, г. Москва, ул. Фотиевой, д. 6, к. 1. Тел.: +7 (499) 530-28-84. Эл. адpec: i.s.shushpanova@mail.ru

Zabuzov Oleg Nikolayevich, Candidate of Political Sciences, Senior Researcher, Institute of Socio-Political Research - Brach of the Federal Center of Theoretical and Applied Sociology of the Russian Academy of Sciences; Associate Professor, Moscow State Linguistic University. Postal address: 6, Bldg. 2, Fotievoi St., Moscow, Russian Federation, 119333. Tel.: +7 (499) 530-28-84. E-mail: zabuzov@mail.ru

Shushpanova Irina Sergeyevna, Candidate of Sociology, Associate Professor, Academic Secretary, Leading Researcher, Institute of Socio-Political Research - Brach of the Federal Center of Theoretical and Applied Sociology of the Russian Academy of Sciences. Postal address: 6, Bldg. 2, Fotievoi St., Moscow, Russian Federation, 119333. Tel.: +7 (499) 530-28-84. E-mail: i.s.shushpa-nova@mail.ru

DOI: $10.17805 /$ zpu.2021.4.7

\title{
Концептуальные подходы к осмыслению интеллектуальной собственности в социогуманитарном знании
}

\author{
A. A. ТОКАРEBA \\ ОТДЕЛЕНИЕ «ВСЕРОССИЙСКАЯ ПАТЕНТНО-ТЕХНИЧЕСКАЯ БИБЛИОТЕКА» \\ ФЕДЕРАЛЬНОГО ИНСТИТУТА ПРОМЫШЛЕННОЙ СОБСТВЕННОСТИ
}

Статья посвящена анализу изменения подходов к феномену интеллектуальной собственности в социокультурном пространстве. В XXI в. продолжаются процессы перехода от производственной экономики к экономике нематериальной, возрастает значимость обладания нематериальными активами, роль знания и технологий. С Античности и до сегодняшнего дня философы и мыслители разделяют материальный мир вещей и идеальный мир идей, имеющие точки соприкосновения. Такого мнения придерживались Платон, Гегель, а также современные ученые. Такую дуальность возможно перенести на сферу интеллектуальной собственности, включающую в себя как идеальную основу авторство и материальное воплощение идеи. В европейской культуре интеллектуальная собственность получила понимание изначально в правовой сфере. Начиная с XVII в. набирал популярность подход, согласно которому интеллектуальный труд приравнен к труду физическому, и автор имеет право на вознаграждение. В результате развития технологий, особенно в XX в., пересматриваются взгляды на интеллектуальный капитал как основной товар в экономике. Правовой характер и экономический характер регулирования интеллектуальной собственности приближаются к собственности материальной. Такая концепция показала противоречия подходов и проблему невозможности однородного регулирования, поставила вопрос внесения множественных оговорок и исключений. В современном мире исследователи приходят к глобальному расширению понимания сферы интеллектуальной собственности как собственности на любую информацию и идею. Таким образом, можно сделать вывод о мультиспециализации интеллектуальной собствен- 
ности, ее глобальном охвате материальных и идеальных сфер, понимание которой даст необходимый толчок развитию общества.

Ключевые слова: интеллектуальная собственность; культура; технология; история; общество; информация; субъект собственности; промышленная собственность; авторское право

\section{ВВЕАЕНИЕ}

Аономическое и технологическое развитие общества до середины XX в. имело технократический характер, представляя собой исключительно борьбу за наращивание темпов промышленного производства. В развитых государствах образовывались механизмы создания, владения и распоряжения собственным материальным имуществом. Философы и мыслители того времени делили собственность на общественную и частную, но определяли любую форму собственности как нечто материальное и вещественное (собственность на землю, производство, предметы искусства, товары).

Bсе более ценными в XXI в. становятся нематериальными активы, обладание которыми в развитых странах (в США, Евросоюзе) доходит до 70\% от общей доли активов государств (Аанько, Вязовикина, 2019: 172). Сегодня наибольшая часть инвестиций приходится на получение товара, связанного со знанием (это может быть программное обеспечение, исследование, разработка технологии, художественное произведение), и в мировой экономике, где активно применяются обороты нематериальных активов, происходят трансформации, ведущие к изменению взаимодействий между субъектами экономики (Хаскел, Вестлейк, 2021: 61-69). В связи с этим перед философами, социологами, культурологами, историками возникла потребность пересмотра классических определений интеллектуальной собственности. Современные отечественные исследователи дают более широкое определение сферы интеллектуальной собственности (Мапытов, 2007: 224-232; Орехов, 2020; Близнец, Борисова, Агаева, 2019; Калачева, Попова, 2018; Мансурова, Мансуров, 2016: 4-7)

Целью исследования является анализ интеллектуальной собственности как социокультурного явления. В рамках данной статьи автором предлагается трактовка интеллектуальной собственности как нематериальных продуктов, возникающих в результате творческой деятельности человека и объективизирующихся в материальном виде. В статье рассматривается эволюция концепции интеллектуальной собственности и особенности изменений социогуманитарного взгляда на феномен.

\section{КОНЦЕПЦИИ МАТЕРИААЬНОГО И ИАЕААЬНОГО НАЧААА ИНТЕАИЕКТУАИЬНОЙ СОБСТВЕННОСТИ}

Интеллектуальная собственность присутствовала в жизни общества на всех стадиях развития цивилизации. Это результаты деятельности, связанной с работой разума человека. Обращение к вопросу вознаграждения творческого труда было в обиходе в сфере правовых, экономических и культурных отношений еще с древних времен, первые упоминания об этом относятся к Аревней Греции 500 г. до н. э. (Понкин, 2013: 124)

Чуть позже, в IV в. до н. э., Платон обосновал различие материального и нематериального миров. Согласно его философии, материальный мир вторичен по 
отношению к миру идей, так как познается за счет чувств и является только произведенным от мира идеального (Рассел, 2001). Все явления и предметы материального мира являются преходящими, они создаются, изменяются и исчезают. В отличие от материи, мир идей находится вне времени, он «застывает» в едином образе и не меняется в зависимости от обстоятельств. Именно стабильность и неподвижность идей позволяют назвать их истинным бытием. В современном понимании «особый мир идеи выступает основой интеллектуальной собственности... эти объекты являются результатом интеллектуальной, духовной деятельности, которая отличается от материальной деятельности» (Гаранина, Егоров, 2007: 61).

Концепции материального и идеального миров рассматривает в особом ключе Г.-В.-Ф. Гегель. В отличие от Платона, немецкий философ разделял собственность на внутреннюю (неотчуждаемую), к которой относились духовные объекты, разум, результаты интеллектуальной и мыслительной деятельности, и внешнюю, в которой основным принципом было обладание вещными объектами: «Я могу отчуждать от себя свою собственность, а именно то, что действительно является собственностью, т. е., с одной стороны, есть мое, а с другой - обладает моментом внешнего наличного бытия. Неотчуждаемы, следовательно, мой разум, моя свобода, моя личность и вообще все то, что составляет необходимое содержание моей свободы» (Гегель, 1971: 199).

Интересную мысль высказал российский философ и антрополог И. А. Аапытов, утверждающий, что «понимание Гегелем собственности сводится к вещной собственности и вводит понятие духовной собственности лишь для полноты классификации» (Аапытов, 2007: 225). Всесторонне рассматривая взгляды на критическое отношение к материальному пониманию собственности, исследователь анализирует также и теорию французского философа и драматурга Габриэля Марселя, который в противовес материальной собственности рассматривает творческую нематериальную собственность как «псевдособственность, которую составляют мои идеи, мои мнения» (там же: 225). Таким образом, сравнивая творческую нематериальную собственность с духовной, И. А. Аапытов приходит к выводу о необходимости непрестанного ее развития.

Идеи различия материального и нематериального (духовного) в XX в. продолжил Карл Поппер, который выдвинул концепцию «трех миров»:

- реальность, существующая объективно;

- состояние сознания и его активность;

- «мир объективного содержания мышления, прежде всего, содержания научных идей, поэтических мыслей и произведений искусства» (Поппер, 1983: 440).

Все три мира не существуют отдельно, а активно взаимодействуют между собой, и чем дальше заходят процессы эволюции человеческого сознания, тем сильнее становится это взаимодействие и возникает все больше точек соприкосновения между физическим миром, мышлением и духовностью (История и философия науки ..., 2011: 28).

Подобную логику взаимопроникновения материального и мира сознания можно перенести на исследования сферы интеллектуальной собственности. Продукт человеческого сознания, его интеллекта обретает физическое воплощение за счет производства и материализации объекта. Это может касаться как промышленной области, так и сферы искусства, когда идея обретает физическую оболочку за счет 
написания книги, создания картины или скульптуры. Иными словами, результат работы разума через приобретение им материальной формы получает все признаки собственности в юридическом и правовом поле. Следовательно, творческая личность, создавшая такой результат, становится обладателем таких же прав и обязанностей, как и в отношении других, материальных, видов собственности. Авойственность природы интеллектуальной собственности связывают с общим понятием «интеллект», которое может относиться как к научно-технической сфере, так и духовной области (Калачева, Попова, 2018: 9).

\section{ФОРМИРОВАНИЕ ТЕОРИИ \\ ИНТЕАИЕКТУААЬНОЙ СОБСТВЕННОСТИ \\ В ЕВРОПЕЙСКОЙ КУ ЬТТУРЕ ХVII-ХХ ВЕКОВ}

Формирование института интеллектуальной собственности берет свое начало в возникновении потребности юридического и правового регулирования отношений между создателями и потребителями результатов интеллектуальной деятельности. Философ и социолог О. В. Стовпец связывает появление первых законодательных актов в Англии в XVII и XVIII вв. с распространением книгопечатания. Исследователь делает вывод о том, что социальная потребность в интеллектуальной продукции сформировала социокультурный запрос на развитие нового правового института интеллектуальной собственности (Стовпец, 2017: 175).

Идеи представления труда как основания для возникновения права собственности выдвинул Ажон ский объект возникает в случае приобретения некоторых благ, когда человек своим трудом производит что-либо. Затраченный человеком труд и порождает право на собственность. В отношении интеллектуальной собственности таким трудом можно считать умственный труд, или «духовное производство» (Мансурова, Мансуров, 2016: 5)

Со временем в этой концепции стали возникать противоречия, потому что исходя из юридических и экономических факторов наделение одними и теми же механизмами регулирования материальной и нематериальной собственности оказалось достаточно проблематично. Стали появляться концепции наделения нематериальной собственности исключительными правами и специальными оговорками, которые требовали специального законодательного урегулирования.

Базовые принципы теории интеллектуальной собственности были заложены французскими мыслителями XVIII в. - Вольтером, Аидро, Гольбахом, Руссо, разработавшими идею «естественного права». Результаты творческого труда приравнивались к материальной собственности (как частной, так и общей), и, следовательно, создатель этого творческого труда имел такое же право распоряжаться своей собственностью, как и промышленник. Современные исследователи отмечают, что в то время философские концепции рассматривали авторское право как продолжение личности автора, поэтому автор имел полное право приобрести право на охрану своего произведения в качестве «части своей личности» (Близнец, 2019: 31).

Тема интеллектуальной собственности в XX в. стала наиболее актуальной в момент, когда произошло глобальное проникновение интеллектуальных продуктов и услуг в жизнь современного общества. Аэниэл Белл, Элвин Тоффлер актуализи- 
ровали вопрос о ценности информации в мире (Белл, 2004; Тоффлер, 2009), Герберт Шиллер сформулировал тезис превращения информации в товар современного общества (Шиллер, 1981).

Таким образом, все концепции объединяет одно положение: любой интеллектуальный и творческий труд должен обладать материальным носителем и вещным атрибутом. И соответственно, в силу вступают юридические права, связанные с материальной собственностью, - обладатель интеллектуальных прав становится полноправным участником взаимоотношений с другими участниками процесса, т. е. без разрешения правообладателя другие физические или юридические лица не имеют права использовать результаты его труда.

\section{СОВРЕМЕННЫЕ ВЗГАЯАЫ \\ НА ИНТЕААЕКТУААЬНУЮ СОБСТВЕННОСТЬ}

Гуманистический смысл интеллектуальной собственности заключается в ее призвании способствовать развитию человека, общества и цивилизации, раскрытию духовного потенциала личности автора, который должен быть уверен в том, что результаты его умственного, духовного труда будут защищены государством.

Обратим внимание на следующее определение интеллектуальной собственности: «Интеллектуальная собственность - формализованные субъективно-индивидуализированные отношения владения, распоряжения и пользования социально значимыми объективированными продуктами интеллектуальной деятельности» (Егоров, 2006: 26).

В расширенном смысле интеллектуальная собственность трактуется как «собственность на любое знание и информацию, на любую идею, на любое идеальное (интеллектуальное, духовное) имущество» (Орехов, 2020: 28). Интеллектуальная собственность имеет отношение к идеальному субстанциональному объекту собственности в противовес материальной, или вещественной, собственности. Генерация знаний и его объективизация являются основными направлениями развития модификации в знании и интеллектуальной собственности, где под генерацией знаний подразумевается процесс творения знаний, а под объективизацией - процесс превращения этого знания в реальность (там же: 29).

Информатизация и цифровизация дают новые технологические возможности использования объектов интеллектуальной собственности, а также формируют новую культуру отношения к ним. Современные зарубежные исследователи в развитии сферы интеллектуальной собственности видят факторы сдерживания для развития инноваций и творчества.

Например, американские правоведы Аарон Перзановски и Ажейсон Шульц, рассматривая современные способы пользования информацией (электронные библиотеки, управление цифровыми правами, интернет-вещей) приходят к выводу, что человек, приобретая тот или иной контент, не получает его в свое полноценное пользование, и поэтому для подтверждения собственной свободы человека необходимо внедрение факторов владения вещной собственностью в цифровую среду (Перзановски, Шульц, 2019).

На свободу владения и сдерживания инноваций за счет слишком широких прав на интеллектуальную собственность также обращает внимание искусствовед и писатель Марта Бускирк (Бускирк, 2021), которая утверждает, что интеллектуальная 
собственность формирует все аспекты современной жизни и культура отношения к ней влияет на художественное самовыражение.

Патентование как изъятие ценностей из инновационной экономики является одной из тем книги экономиста Марианы Маццукато «Ценность всех вещей». Автор утверждает, что система патентования «разбалансирована» между процессами присвоения экономических выгод и раскрывающей функцией патентов: «нынешнее господство нарратива о предпринимателях как создателях ценности сместило баланс патентной системы от акцента на распространении знания в направлении частного вознаграждения» (Маццукато, 2021: 290).

Несмотря на достаточно пессимистические взгляды зарубежных исследователей, мы убеждены, что интеллектуальная собственность играет важную роль в инновационном и экономическом развитии любого государства. Как было уже сказано, в развитых странах доля нематериальных активов доходит до 70\%. Также мы убеждены, что существует прямая зависимость обладания охранными документами на результаты интеллектуальной деятельности и ВВП стран мира. Например, страны с высоким ВВП (США, Китай) являются лидерами по обладанию патентами и количеством поданных заявок на регистрацию результатов интеллектуальной собственности (Токарева, 2020).

\section{ЗАКАЮЧЕНИЕ}

На основании проведенного исследования можно сделать следующий вывод: концепция интеллектуальной собственности претерпела значительные изменения, пройдя путь от правового регулирования деятельности отдельных категорий создателей интеллектуального продукта до всеобъемлющего понимания собственности как собственности на информацию, когда-либо представленную.

Исходя из идей вещного и идеального миров, сложилась базовая концепция точек соприкосновения и взаимодействия мысли и объекта. Ее авторы уверены, что идея в том или ином виде воплощается в материальные объекты, где приобретает форму и расширенные функции деятельности. В настоящее время очевидно, что интеллектуальная собственность обладает уникальным свойством, представляя собой результат творческого (идеального, духовного) начала автора, выраженный в объективизированной материальной форме.

С юридической и правовой точек зрения интеллектуальная собственность это собственность особого рода, требующая специального регулирования и имеющая множество оговорок, поскольку главная особенность такой собственности в том, что она нематериальна и ее легко копировать. Интеллектуальная собственность несет в себе начала, объединяющие как гуманитарные, так и технические области знания, и зачастую границы определений сильно размыты. Именно концептуальное понимание интеллектуальной собственности как нематериального блага вызывает затруднения в правоприменительной и юридической деятельности.

В постиндустриальном обществе, в котором одна из основных черт - инновационность и обладание знаниями, интеллектуальная собственность оказывается основополагающей для технологического и экономического развития. Новое осмысление интеллектуальной собственности становится ключевым не только в понимании социокультурных процессов, но и закладывает базис осмысления творческого потенциала научно-технологического и цивилизационного развития обще- 
ства. На наш взгляд, необходимо продолжить изучение явления интеллектуальной собственности, наделенного культурно-философским смыслом, что даст возможность развитию деятельности сферы интеллектуальной собственности в постиндустриальном обществе.

\section{СПИСОК АИТЕРАТУРЫ}

Гаранина, О. А., Егоров, С. В. (2007) Философские предпосылки исследования интеллектуальной собственности // Научный вестник Московского государственного технического университета гражданской авиации. Серия История, философия, социология. № 113. C. 59-64.

Гегель, Г. В. Ф. (1971) Философская пропедевтика // Гегель Г. В. Ф. Работы разных лет. В 2 т. / сост., общ. ред. А. В. Гулыги. М. : Мысль. Т. 2. 630 с. С. 7-213.

Аанько, Т. П., Вязовикина, А. С. (2019) Маркетинговый потенциал создания и использования нематериальных активов в условиях рейтингового позиционирования стран // Beстник Белгородского университета кооперации, экономики и права. № 5 (78). С. 169-180.

Егоров, С. В. (2006) Философско-методологические аспекты интеллектуальной собственности и ее правовой защиты : автореф. дис. ... канд. филос. наук. М. 26 с.

Белл, А. (2004) Грядущее постиндустриальное общество: опыт социального прогнозирования / пер. с англ. под ред. В. А. Иноземцева. Москва : Academia. 783 с.

Близнец, И. А., Борисова М. С., Агаева, К. А. (2019) Интеллектуальная собственность в современном мире / под ред. И. А. Близнеца. М. : Проспект. 669 с.

История и философия науки. Проблема научного познания в концепции К. Поппера : метод. указ. (2011) / сост. О. В. Беззубова. СПб. : СПбГАСУ. 28 с.

Калачева, Т. А., Попова, О. П. (2018) Интеллектуальная собственность под охраной закона. Хабаровск : Изд-во Тихоокеан. гос. ун-та, 210 с.

Аапытов, И. А. (2007) Социальные качества духовной собственности (философские аспекты) // Иичность. Культура. Общество. Т. 9. № 4 (39) С. 224-232.

Аапытов, И. А. (2008) Социально-философские аспекты невещественной собственности в информационном обществе. Ижевск : КнигоГрад, 318 с.

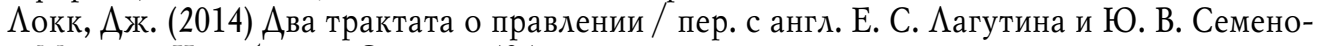
вой. Москва ; Челябинск : Социум, 494 с.

Мансурова, Г. И., Мансуров П. М. (2016) Содержание и генезис понятия «интеллектуальная собственность» // Вестник Удьяновского государственного технического университета. № 1(73) C. 4-7.

Маццукато, М. (2021) Ценность всех вещей: Создание и изъятие в мировой экономике / пер. с англ. Н. Проценко ; под науч. ред. Н. Афанасова, А. Павлова. М. : Национальный исследовательский университет «Высшая школа экономики». $408 \mathrm{c.}$

Орехов, А. М. (1997) Интеллектуальная собственность как объект философского исследования // Вестник Московского университета. Серия 7. Философия. № 1. С. 31-48.

Орехов, А. М. (2020) Интеллектуальная собственность: эскизы общей теории. Москва : ИНФРА-М. 160 c.

Перзановски, А., Шульц, Аж. (2019) Конец владения: личная собственность в цифровой экономике / пер. с англ. Е. Аебедева ; ред. Е. В. Попова. М. : Издательский дом «Аело» РАНХиГС. $352 \mathrm{c}$.

Понкин, И. В. (2013) История развития права интеллектуальной собственности. Первые нормативные правовые акты, касавшиеся вопросов авторского права // Вестник РУАН. Серия Юридические науки. № 3 С. 124-129.

Поппер, К. Р. (1983) Иогика и рост научного знания / пер. с англ. $\Lambda$. В. Блинникова, В. Н. Брюшинкина, Э. А. Наппельбаум, А. А. Никифорова ; сост., общ. реА. В. Н. Садовского. М. : Прогресс. 605 с.

Рассел, Б. (2001) История западной философии : в 3 кн. / пер. с англ. В. В. Целищева. СПб. : Азбука. 960 с. 
Токарева, А. А. (2020) Культура интеллектуальной собственности России в условиях перехода к новому технологическому укладу // Культура и цивилизация. Т. 10. №5А. C. 206-216. DOI: 10.34670/AR.2020.22.24.025

Тоффлер, Э. (2009) Третья волна / пер. с англ. К. Ю. Бурмистрова и др. М. : АСТ. 795 c.

Хаскел, Аж, Вестлейк, С. (2021) Капитализм без капитала: подъем нематериальной экономики // Экономическая социология. Т. 22. № 1. С. 61-69.

Buskirk, M. (2021) Is It Ours?: Art, Copyright, and Public Interest. Oakland, CA: University of California Press. 304 p.

Schiller, H. I. (1981) Who knows: Information in the Age of the Fortune 500. Norwood, NJ : Ablex Publishing. 150 p.

Stovpets, O. V. (2017) A Philosophical View on the Socio-cultural Roots for Intellectual Property's Institutionalization // ISJ Theoretical \& Applied Science. Vol. 46. Issue 02. P. 173-179.

Аата поступления: 27.08.2021 2.

\author{
CONCEPTUAL APPROACHES \\ TO UNDERSTANDING INTELLECTUAL PROPERTY \\ IN SOCIO-HUMANITARIAN KNOWLEDGE \\ A. A. TOKAREVA \\ "All-Russian Patent and Technical Library" Division, \\ FEDERAL INSTITUTE OF INDUSTRIAL PROPERTY
}

The article analyzes the changes in approaches to the phenomenon of intellectual property in the socio-cultural space. In the 21st century, the processes of transition from a manufacturing economy to an intangible economy are continuing, and significance of possessing intangible assets and the role of knowledge and technology are increasing. From ancient times to the present day philosophers and thinkers contradistinguish the material world of things and the perfect world of ideas having points of contact. Plato, Hegel held such an opinion, as well as modern thinkers. This dualism can be projected to the sphere of intellectual property including both the ideal basis of authorship and the material idea embodiment. In European culture intellectual property initially received recognition in the legal sphere. Since the 17 th century, the approach of equating intellectual and physical labor with acknowledging the author's right for reward began to spread. With the technological development, especially in the 20th century, the views on intellectual capital as the main commodity in the economy are revised. The legal and economic nature of regulating intellectual property brings it closer to material property. This concept revealed the discrepancy of the concepts and the impossibility of uniform regulation, which raised the issue of introducing multiple reservations and exceptions. In the modern world researchers come to a global extension of understanding the field of intellectual property as the ownership of any information and idea. Thus, it is possible to draw a conclusion about the multi-specialization of intellectual property and its global coverage of material and ideal spheres; understanding this will give the necessary impetus to social development.

Keywords: intellectual property; culture; technology; history; society; information; subject of ownership; industrial property; copyright

\title{
REFERENCES
}

Garanina, O. D. and Egorov, S. V. (2007) Filosofskie predposylki issledovanija intellektual'noj sobstvennosti. Nauchnyj vestnik Moskovskogo gosudarstvennogo tebnicheskogo universiteta grazhdanskoi aviatsii. Serija Istorija, filosofija, sociologija, no. 113, pp. 59-64. (In Russ.). 
Hegel, G. W. F. (1971) Philosophical Propaedeutics / In: Hegel G. W. F. Raboty raznykb let. In 2 vols.; comp., ed. by A. Guliga; transl. from German by B. Dragun. Vol. 2. Moscow, Mysl'. 630 p. (In Russ.).

Dan'ko, T. P. and Vjazovikina, A. S. (2019) Marketingovyj potencial sozdanija i ispol'zovanija nematerial'nyh aktivov v uslovijah rejtingovogo pozicionirovanija stran. Vestnik Belgorodskogo universiteta kooperacii, jekonomiki i prava, no. 5 (78), pp. 169-180. (In Russ.).

Egorov, S. V. (2006) Filosofsko-metodologicheskie aspekty intellektual' noj sobstvennosti i ee pravovoj zashbity. Abstract of the diss. ... Candidate of Philosophy. Moscow. 26 p. (In Russ.).

Bell, D. (2004) Gryaduchshee postindustrialnoe obchshestvo: opyt socialnogo prognozirovaniya / trans. from English; ed. by V. Inozemtsev. Moscow, Academia. 783 p. (In Russ.).

Bliznets, I. A., Borisova, M. S. and Agaeva, K. A. (2019) Intellektual' naia sobstvennost'v sovremennom mire / ed. by I. A. Bliznets. Moscow, Prospekt. 669 p. (In Russ.).

Istorija i filosofija nauki. Problema nauchnogo poznanija v koncepcii K. Poppera: methodical instructions / comp. by O. V. Bezzubova (2011) St. Petersburg, Saint Petersburg State University of Architecture and Civil Engineering. 28 p. (In Russ.).

Kalacheva, T. L., Popova, O. P. (2018) Intellektual'naja sobstvennost' pod obranoj zakona. Habarovsk, Pacific State University. 210 p. (In Russ.).

Lapytov, I. A. (2007) Social'nye kachestva duhovnoj sobstvennosti (filosofskie aspekty) Lichnost'. Kul'tura. Obsbbestvo, vol. 9, no. 4 (39), pp. 224-232. (In Russ.).

Lapytov, I. A. (2008) Social' no-filosof skie aspekty neveshbestvennoj sobstvennosti v informacionnom obshbestve. Izhevsk, KnigoGrad. 318 p. (In Russ.).

Locke, J. (2014) Two Treatises of Government / transl. from English by E. Lagutin and J. Semenova. Moscow, Chelyabinsk, Socium. 494 p. (In Russ.).

Mansurova, G. I. and Mansurov, P. M. (2016) Soderzhanie i genezis ponjatija «intellektual' naja sobstvennost'. Vestnik Ul'janovskogo gosudarstvennogo tebnicheskogo universiteta, no. 1 (73), pp. 4-7. (In Russ.).

Mazzucato, M. (2021) Tsennost' vseb vechshei: Sozdanie i izyatie v mirivoi economike / transl. from English by N. Protsenko; ed. by N. Afanasov, A. Pavlov. Moscow, National Research University Higher School of Economics. 408 p. (In Russ.).

Orehov, A. M. (1997b) Intellektual'naja sobstvennost' kak ob'ekt filosofskogo issledovanija. Vestnik Moskovskogo Universitetata, Seria Filosofija, no 1, pp. 31-48. (In Russ.).

Orehov, A. M.(2020a) Intellektual'naja sobstvennost': jeskizy obsbbej teorii. Moscow, INFRA-M. 160 p. (In Russ.).

Perzanowski, A. and Schultz, J. (2019) Konec vladeniya: lichnaya sobstvennost' $v$ cifrovoi economike / transl. from English by E. Lebedev; ed. by E. Popova. Moscow, Delo. 352 p. (In Russ.).

Ponkin, I. V. (2013) Istorija razvitija prava intellektual'noj sobstvennosti. Pervye normativnye pravovye akty, kasavshiesja voprosov avtorskogo prava. Vestnik RUDN. Serija Juridicheskie nauki, no 3, pp. 124-129. (In Russ.).

Popper, K. R. (1983) The Logic of Scientific Discovery / transl. from English by L. Blinnikov, V. Brushinkin, E. Nappelbaum, A. Nikiforov; comp., ed. by V. Sadovski. Moscow, Progress. 605 p. (In Russ.).

Rassel, B. (2001) History of Western Philosopby: In 3 vol. / transl. from English by V. V. Celishhev. St. Petersburg, Azbuka. 960 p. (In Russ.).

Stovpets, O. V. (2017) A Philosophical View on the Socio-cultural Roots for Intellectual Property's Institutionalization. ISJ Theoretical \& Applied Science, iss. 02, vol. 46, pp. 173-179. (In Russ.).

Tokareva, A. A. (2020) Kul'tura intellektual'noj sobstvennosti Rossii v uslovijah perehoda k novomu tehnologicheskomu ukladu. Kul'tura $i$ civilizacija. Vol. 10, no 5A, pp. 206-216. (In Russ.).

Toffler, E. (2009) Tretia volna / transl. from English by K. Burmistrov et al. Moscow, AST. 795 p. (In Russ.). 
Haskel, J. and Westlake, S. (2021) Kapitalizm bez kapitala: pod'em nematerialnoj ekonomiki. Economicheskaya sociologiya, vol. 22, 1, pp. 61-69. (In Russ.).

Schiller, H. I. (1981) Who knows: Information in the Age of the Fortune 500. Norwood, NJ: Ablex Publishing. 150 p.

Buskirk, M. (2021) Is It Ours?: Art, Copyright, and Public Interest. Oakland, CA: University of California Press. 304 p.

Submission date: 27.08 .2021$.

Токарева Анастасия Александровна - заместитель заведующего информационно-библиографическим отделом отделения «Всероссийская патентно-техническая библиотека» Федерального института промышленной собственности. Адрес: 121059, г. Москва, Бережковская наб., д. 24. Тел.: +7 (499) 240-64-13. Эл. адрес: otd5729@rupto.ru

Tokareva Anastasia Aleksandrovna, Deputy Head, Information and Bibliography Department, "All-Russian Patent and Technical Library" Division, Federal Institute of Industrial Property. Postal Address: 24, Berezhkovskaya Emb., Moscow, Russian Federation, 121059. Tel. +7 (499) 240-64-13. E-mail: otd5729@rupto.ru 